\title{
Switch-like genes populate cell communication pathways and are enriched for extracellular proteins Adam Ertel and Aydin Tozeren*
}

Address: Center for Integrated Bioinformatics, School of Biomedical Engineering, Science and Health Systems, Drexel University, 3141 Chestnut Street, Philadelphia, PA 19104, USA

Email: Adam Ertel - ame28@drexel.edu; Aydin Tozeren* - aydin.tozeren@drexel.edu

* Corresponding author

Published: 4 January 2008

BMC Genomics 2008, 9:3 doi:10.1/86/|47|-2164-9-3
Received: 24 May 2007

Accepted: 4 January 2008

This article is available from: http://www.biomedcentral.com/l47/-2/64/9/3

(c) 2008 Ertel and Tozeren; licensee BioMed Central Ltd.

This is an Open Access article distributed under the terms of the Creative Commons Attribution License (http://creativecommons.org/licenses/by/2.0), which permits unrestricted use, distribution, and reproduction in any medium, provided the original work is properly cited.

\begin{abstract}
Background: Recent studies have placed gene expression in the context of distribution profiles including housekeeping, graded, and bimodal (switch-like). Single-gene studies have shown bimodal expression results from healthy cell signaling and complex diseases such as cancer, however developing a comprehensive list of human bimodal genes has remained a major challenge due to inherent noise in human microarray data. This study presents a two-component mixture analysis of mouse gene expression data for genes on the Affymetrix MG-U74Av2 array for the detection and annotation of switch-like genes. Two-component normal mixtures were fit to the data to identify bimodal genes and their potential roles in cell signaling and disease progression.

Results: Seventeen percent of the genes on the MG-U74Av2 array (I5I9 out of 909I) were identified as bimodal or switch-like. KEGG pathways significantly enriched for bimodal genes included ECM-receptor interaction, cell communication, and focal adhesion. Similarly, the GO biological process "cell adhesion" and cellular component "extracellular matrix" were significantly enriched. Switch-like genes were found to be associated with such diseases as congestive heart failure, Alzheimer's disease, arteriosclerosis, breast neoplasms, hypertension, myocardial infarction, obesity, rheumatoid arthritis, and type I and type II diabetes. In diabetes alone, over two hundred bimodal genes were in a different mode of expression compared to normal tissue.

Conclusion: This research identified and annotated bimodal or switch-like genes in the mouse genome using a large collection of microarray data. Genes with bimodal expression were enriched within the cell membrane and extracellular environment. Hundreds of bimodal genes demonstrated alternate modes of expression in diabetic muscle, pancreas, liver, heart, and adipose tissue. Bimodal genes comprise a candidate set of biomarkers for a large number of disease states because their expressions are tightly regulated at the transcription level.
\end{abstract}

\section{Background}

Gene expression microarrays have served as a useful tool for assaying large-scale similarities and differences among conditions including tissue types [1], stages of development $[2,3]$, and disease states in humans $[4,5]$ and model organisms [6]. Initial microarray classification studies such as those presented in $[4,5]$ were able to characterize similarities and differences among samples based on mRNA expression level for large gene sets. More recent studies have made use of biological annotation, such as 
Gene Ontology (GO) or Kyoto Encyclopedia of Genes and Genomes (KEGG) pathways [7] to project changes in individual genes onto biological functions $[8,9]$. Existing biological annotation is also a useful supplement to machine learning techniques used for determining regulatory connections $[10,11]$. These techniques are sensitive to differential expression as well as small concerted changes in levels of gene expression, yet they may not adequately address changes with respect to the global behavior of gene expression - where transcript levels may either be tightly regulated within a narrow range, or fluctuate widely as a function of environmental cues or tissue specialization.

Efforts to explain biological functions associated with single genes or sets of related genes often focus on variations of gene expression across diverse tissue types. Identification of genes as tissue-selective and tissue-specific is useful for highlighting their biological function, as well as providing reference/context for disease states. Identification of tissue-specific and tissue-selective genes is commonly based on present/absent calls, requiring a global threshold [12-14]. Tissue-specific behavior has also been identified using statistical tests to compare sample distributions between tissue types $[1,15,16]$. Other approaches have used a numeric value representing the degree of tissue specificity within one tissue or tissue subset versus all others $[17,18]$. These studies are typically performed on a small number of samples within each tissue type; they nevertheless effectively describe genes with large variation between distinct tissues.

Efforts have been made to place gene expression in context of global behavior using descriptors such as breadth of gene expression [12] and distributions characteristics that represent ubiquitous, binary, or graded regulation [19-23]. Ubiquitously expressed "housekeeping" genes are defined as those highly expressed with little variation across conditions, and have been identified in humans using large-scale microarray studies $[1,24]$. While breadth of expression and housekeeping behavior have been established using genome-scale measurements, present descriptions of graded and binary genes have typically been produced using single-gene studies $[19,20]$. These studies have demonstrated that changes in gene expression levels can occur continuously or in a binary switchlike manner in response to extracellular changes. Binary modes of gene expression potentially correspond to those proteins with tight regulation at the transcript level. As such their identification is useful in the exposition of the multiple modes of gene expression regulation observed in eukaryotes.

In this study, we expand on the existing literature on gene expression profile distributions and determine a compre- hensive list of bimodal genes along with their functional annotation. Our preliminary computations based on large collection of human microarray data indicated difficulties identifying profiles of bimodal expression due to a great degree of subject variability and noise. For this reason, the present study focuses on murine microarray data containing approximately 400 samples, all obtained using the Affymetrix MG-U74Av2 platform (Table 1) [3,6,2539]. This new database allowed us to effectively apply a two-component mixture model to hundreds of data points for each gene and identify bimodal profiles. Moreover, bimodal genes with altered modes of expression were identified in microarray data for type I and type II diabetes (Table 2) $[6,29,40,41]$. Results point to important roles that bimodal (switch-like) genes play within the extracellular environment in health and disease. Bimodal genes, because they are tightly controlled around two distinct modes at the transcript level, serve as targets in drug development. Moreover, bimodal genes encoding for extracellular proteins may serve as biomarkers in targeted proteomic studies.

\section{Results \\ Identification of bimodal genes in the mouse genome}

Our method identified 1519 bimodal genes out of the 9091 unique genes (17\%) on the MG-U74Av2 array (see Additional file 1). The total number of bimodal genes was not sensitive to the p-value cutoff for bimodal versus skewed normal representations of the gene expression distribution within the ranges considered: the bimodal gene list increased by only three genes when the p-value was increased from 0.001 to 0.01 . Similarly, gene expression outliers were not important contributors to the bimodal gene list. When we deleted the three largest gene expression values from the gene expression profile of each gene and ran our procedure for identification of bimodal genes, the resulting bimodal gene list turned out to be identical to our standard set of genes minus five genes. See Additional file 1 for a table that provides a comprehensive list of bimodal genes for the mouse genome. Columns of this table are composed of the following entities: Affymetrix probe ID, Entrez gene ID, gene symbol, human orthologs, log likelihood test statistic, estimated p-value, and maximum overlap $A$, representing the misclassification area between modes. Also listed for each gene in this table are parameters indicating the standardized distance between means $D$, the mixture parameter $\pi$, and the log RMA gene expression threshold value $X_{T}$ separating high and low expression modes. The information on this table constitutes a priori data needed to identify the high expression or low expression modes of each gene in any given sample. The table can be used to identify altered modes of expression in disease states provided that these genes preserve their bimodal expression patterns. The human orthologs of the bimodal mouse genes are listed 
Table I: Mouse gene expression datasets and tissue types composing our healthy dataset.

\begin{tabular}{|c|c|c|c|c|c|}
\hline Healthy Tissue Type & Accession No. & Source & Reference & Samples & Total \\
\hline \multirow[t]{2}{*}{ Adipose } & GSE480 & GEO & N/A & 4 & 6 \\
\hline & GSE2899 & GEO & {$[6]$} & 2 & \\
\hline Adrenal & GSEI 674 & GEO & {$[25]$} & 6 & 6 \\
\hline \multirow[t]{2}{*}{ Brain } & GSE3327 & GEO & [26] & 87 & 89 \\
\hline & GSE480 & GEO & $\mathrm{N} / \mathrm{A}$ & 2 & \\
\hline \multirow[t]{2}{*}{ Colon } & GSE2। 72 & GEO & {$[27]$} & 4 & 5 \\
\hline & E-MEXP-402 & Array Express & $\mathrm{N} / \mathrm{A}$ & I & \\
\hline Epidermal & GSEI912 & GEO & [28] & 25 & 25 \\
\hline \multirow[t]{3}{*}{ Heart } & GSE77 & GEO & $\mathrm{N} / \mathrm{A}$ & 30 & 38 \\
\hline & GSE46I6 & GEO & [29] & 6 & \\
\hline & GSE480 & GEO & $\mathrm{N} / \mathrm{A}$ & 2 & \\
\hline Kidney & E-MEXP-495 & Array Express & {$[30]$} & 3 & 3 \\
\hline \multirow[t]{2}{*}{ Liver } & E-MEXP-24I & Array Express & {$[31]$} & 6 & 8 \\
\hline & GSE2899 & GEO & {$[6]$} & 2 & \\
\hline \multirow[t]{3}{*}{ Lung } & GSE485 & GEO & N/A & 18 & 26 \\
\hline & GSE495 & GEO & N/A & 6 & \\
\hline & GSE480 & GEO & N/A & 2 & \\
\hline \multirow[t]{2}{*}{ Mammary } & GSE583I & GEO & $N / A$ & 9 & 15 \\
\hline & E-MEXP-892 & Array Express & [32] & 6 & \\
\hline \multirow[t]{4}{*}{ Muscle } & GSE469 & GEO & [33] & 54 & 64 \\
\hline & GSEI 659 & GEO & [29] & 6 & \\
\hline & GSE2899 & GEO & {$[6]$} & 2 & \\
\hline & GSE480 & GEO & N/A & 2 & \\
\hline Ovary & GSEI 359 & GEO & [3] & 10 & 10 \\
\hline \multirow[t]{2}{*}{ Pancreas } & GSE769 & GEO & [34] & 3 & 5 \\
\hline & GSE2899 & GEO & {$[6]$} & 2 & \\
\hline Peripheral Blood & GSE3039 & GEO & [35] & 12 & 12 \\
\hline Small Intestine & GSE765 & GEO & $\mathrm{N} / \mathrm{A}$ & 3 & 3 \\
\hline Spleen & GSE5306 & GEO & $N / A$ & 12 & 12 \\
\hline Stomach & E-MEXP-402 & Array Express & $N / A$ & $\mathrm{I}$ & 1 \\
\hline \multirow[t]{3}{*}{ Testis } & GSE926 & GEO & {$[36]$} & 22 & 49 \\
\hline & GSE640 & GEO & [37] & 17 & \\
\hline & GSEI 358 & GEO & [3] & 10 & \\
\hline \multirow[t]{2}{*}{ Thymus } & GSE2585 & GEO & [38] & 8 & 11 \\
\hline & GSE85 & GEO & [39] & 3 & \\
\hline All Healthy Tissues & & & & & 388 \\
\hline
\end{tabular}

in this table (Additional file 1) for reference and their bimodal behavior in humans would have to be verified in future studies.
Tissue similarity based on common modes of expression within bimodal genes

Next we considered similarity of the nineteen tissues for which we had extensive microarray data. As detailed in the methods section, we based our criteria of tissue similarity

Table 2: Mouse gene expression datasets and tissue types composing our diabetes dataset.

\begin{tabular}{lcccc}
\hline Diabetic Tissue Type & Accession No. & Source & Reference & Samples \\
\hline Adipose (Type II) & GSE2899 & GEO & {$[6]$} & 2 \\
Heart (Type I) & GSE46I6 & GEO & {$[29]$} & 6 \\
Liver (Type II) & GSE2899 & GEO & {$[6]$} & 2 \\
Muscle (Type I) & GSEI659 & GEO & {$[29]$} & 6 \\
Muscle (Type II) & GSE2899 & GEO & {$[6]$} & 2 \\
Pancreas (Type I) & GSEI623 & GEO & {$[40]$} & 6 \\
Pancreas (Type II) & GSE2899 & GEO & {$[6]$} & 2 \\
Peripheral Blood (Type I) & GSEI4I9 & GEO & {$[4 I]$} & 22
\end{tabular}


on the lists of tissue-selective bimodal genes in common within each unique pair of tissues. Figure 1 indicates that commonality in the set of tissue-selective bimodal genes is indicative of tissue similarity. The number of tissueselective bimodal genes in the "high" mode for each tissue type is provided as the bottom number in the diagonal of Figure $1 \mathrm{~A}$, while the top number represents genes that may be considered tissue-specific; they are expressed in the "high" mode for that single tissue and the "low" mode for all others. The remaining matrix elements of Figure 1A

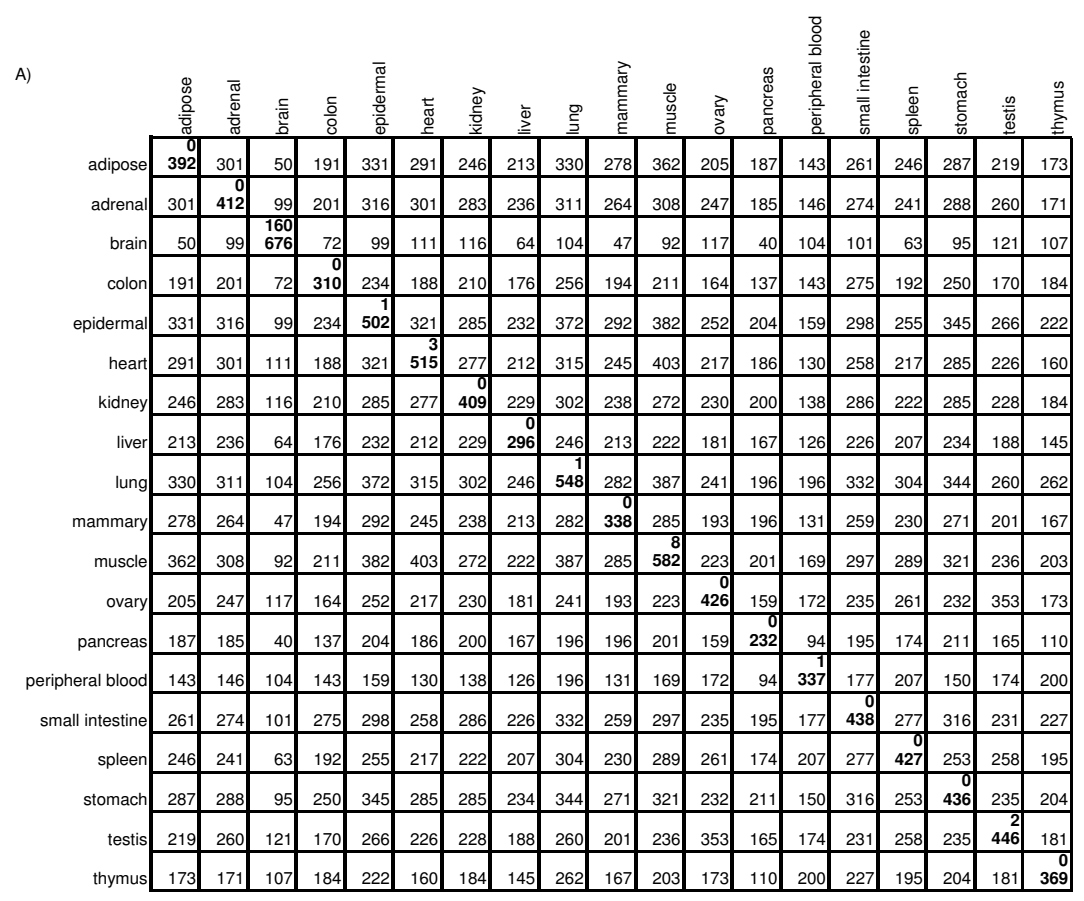

B)

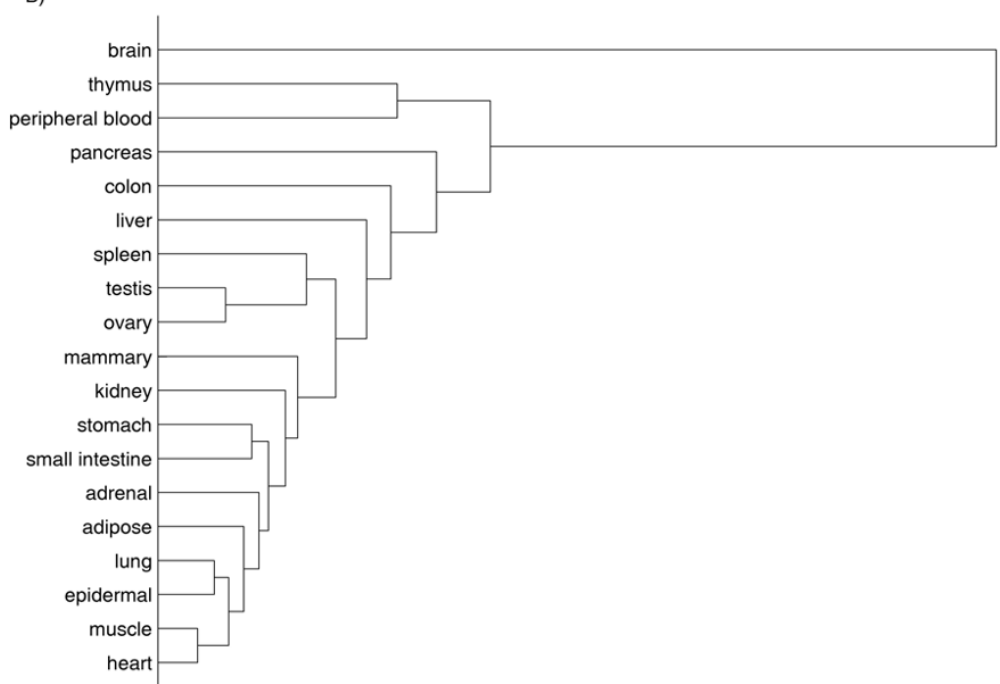

Figure I

Tissue selective genes common among nineteen tissue types. A) The diagonal contains a top number corresponding to tissue-specific switch-like genes expressed in a given tissue and a bottom number identifying the total number of tissueselective switch-like genes expressed in that tissue. B) A dendrogram representing tissue similarity based on tissue-selective expression of bimodal genes. 
are the number of bimodal genes in the "high" mode for both of the two tissue types designated in the row and column headings. We performed hierarchical clustering of the nineteen tissues based on sets of bimodal genes shared between them, to further demonstrate the role bimodal genes may play in tissue similarity. The dendrogram in Figure 1B was computed using hierarchical clustering with average linkage, using one over the number of bimodal genes shared between two tissues (from Figure 1A) as the distance metric. In several examples, tissues with similar function cluster together, such as stomach and small intestine, heart and skeletal muscle, thymus and peripheral blood, and the reproductive tissues ovary and testis, while brain clusters distinctly apart from all other tissues. Other groupings such as adipose, lung, adrenal, and epidermal tissue may occur because of signaling motifs shared among these tissue types. Our predications of tissue similarity are consistent with previous results that group human tissues by hierarchical clustering $[1,12]$.

\section{Functional enrichment analysis indicates bimodal genes' involvement with the extracellular environment}

Interaction with the extracellular environment appeared to be a common theme when we tested our bimodal gene subsets for enrichment among KEGG pathways and GO terms. Our findings for enriched KEGG pathways and GO categories are summarized in Tables 3 and 4, respectively. The tables include enrichment scores, defined as the ratio of the observed number of genes over the expected number of genes from the subset of interest, and p-values for each entry calculated from a hypergeometric test [42] for the bimodal gene set against all unique genes on the MG-U74Av2 array. KEGG pathways that were enriched for bimodal genes include cell communication, ECM-receptor interaction, focal adhesion - all pathways that mediate cell communication with the extracellular environment (Table 3). Figures 2 and 3 identify the placement of bimodal genes (marked as orange) in ECM-receptor interaction and focal adhesion pathways, respectively. Structural proteins that are bound by integrin receptors - collage, laminin and fibronectin subunits - are largely encoded by bimodal genes, confirming the fact that the multiple signaling roles of integrins are coupled with the extracellular environment [43]. The focal adhesion pathway shown in Figure 3 illustrates bimodal genes that mediate cell communication at the interior of the cell including genes that encode proteins involved in phosphorylation (ERK1/2, JNK, MEK1, MLCK, PAK, and PDK1). Bimodal genes populate GO cellular component categories such as axons, basal lamina, basement membrane, cytoskeleton and extracellular matrix, and they are principally involved in the biological processes for ion transport, synaptic transmission, cytoskeletal organization and cell adhesion (Table 4). The abundance of genes with bimodal expression within the cell communication, focal adhesion, and ECM pathways suggests aspects of these activities are enabled and disabled at the transcript level. Additionally, KEGG pathways for sugar metabolism are enriched with bimodal genes, reminiscent of the switch-like regulation of lactose metabolism in bacteria.

\section{Altered modes of bimodal genes in diabetes}

We identified bimodal genes that are expressed in an alternate mode within disease states for type I and type II diabetes. Comparisons of microarray samples for diabetes against samples for healthy tissue yielded nearly 200 genes with expression changes from "low" to "high" and "high" to "low" expression modes in skeletal muscle (Table 5). Changes were dominated by switching from "high" to "low" in skeletal muscle in both type I and type II diabetes. The bimodal genes with altered states in diabetes type I and II are enriched in pathways involved in communication and natural killer cell mediated cytotoxicity (Table 6). Additional file 2 provides a list of all bimodal genes with altered modes of expression in diabetes. The bimodal genes altered in diabetic skeletal muscle are mapped onto the ECM-receptor interaction and focal adhesion pathways, shown in Figures 2 and 3, respectively. As shown in these figures, collagen, fibronectin and tenascin are downregulated in diabetes type I and II transitioning from "high" to "low" expression whereas collagen receptor CD36 is switched from "low" to "high" expression in diabetes, perhaps as compensation for lower expression of extracellular matrix proteins. The list of bimodal genes association with diabetes may provide clues as to the changes that occur in gene regulation path-

Table 3: Enriched KEGG pathways for switch-like genes. Enrichment scores are the number of observed genes over the number of expected genes. P-values were computed using the hypergeometric distribution.

\begin{tabular}{lcccc}
\hline KEGG pathway & Genes observed & Genes expected & Ration of enrichment & P-values $\leq 0.0$ I \\
\hline Cell Communication & 35 & 14.37 & 2.44 & $1.01 \mathrm{E}-07$ \\
ECM-receptor interaction & 26 & 10.69 & 2.43 & $4.57 \mathrm{E}-06$ \\
Focal adhesion & 42 & 24.23 & 1.73 & $1.47 \mathrm{E}-04$ \\
Fructose and mannose metabolism & 13 & 5.68 & 2.29 & $2.18 \mathrm{E}-03$ \\
Glycolysis/Gluconeogenesis & 16 & 8.19 & 1.95 & 1.62 \\
Long-term depression & 17 & 9.36 & 1.82 & $8.07 \mathrm{E}-03$ \\
Tight junction & 24 & & 1.87 & $1.23 \mathrm{E}-03$ \\
\hline
\end{tabular}


Table 4: Enriched GO terms for switch-like genes. Terms are organized by cellular component (CC), biological process (BP), and molecular function (MF). Enrichment scores are the number of observed genes over the number of expected genes. P-values were computed using the hypergeometric distribution.

\begin{tabular}{|c|c|c|c|c|c|}
\hline & GO term & Genes observed & Genes expected & Ration of enrichment & P-values $\leq 0.001$ \\
\hline \multirow{15}{*}{$\begin{array}{l}\mathrm{C} \\
\mathrm{C}\end{array}$} & axon & 19 & 7.02 & 2.71 & I.40E-05 \\
\hline & basal lamina & 9 & 2.67 & 3.37 & $3.68 \mathrm{E}-04$ \\
\hline & basement membrane & 14 & 5.35 & 2.62 & 2.94E-04 \\
\hline & collagen & 14 & 5.01 & 2.79 & $1.26 \mathrm{E}-04$ \\
\hline & cytoskeleton & 65 & 39.27 & 1.66 & I.35E-05 \\
\hline & extracellular matrix & 7 & 1.84 & 3.81 & 6.34E-04 \\
\hline & extracellular matrix (sensu Metazoa) & 63 & 26.57 & 2.37 & $0.00 \mathrm{E}+00$ \\
\hline & muscle myosin complex & 6 & 1.17 & 5.13 & I.30E-04 \\
\hline & postsynaptic membrane & 18 & 7.85 & 2.29 & $3.20 \mathrm{E}-04$ \\
\hline & sarcolemma & 8 & 2.17 & 3.68 & $3.47 \mathrm{E}-04$ \\
\hline & sarcoplasmic reticulum & 6 & 1.34 & 4.49 & 4.44E-04 \\
\hline & synapse & 24 & 9.52 & 2.52 & $5.03 E-06$ \\
\hline & synaptic vesicle & 15 & 6.35 & 2.36 & 6.87E-04 \\
\hline & synaptosome & 12 & 4.51 & 2.66 & 6.69E-04 \\
\hline & troponin complex & 6 & 1.34 & 4.49 & 4.44E-04 \\
\hline \multirow[t]{11}{*}{$\mathrm{BP}$} & calcium ion transport & 19 & 8.02 & 2.37 & I.32E-04 \\
\hline & cell adhesion & 88 & 50.79 & 1.73 & 4.4IE-08 \\
\hline & cytoskeleton organization and biogenesis & 29 & 14.54 & 1.99 & I.09E-04 \\
\hline & ion transport & 62 & 42.11 & 1.47 & 7.54E-04 \\
\hline & muscle contraction & 24 & 8.86 & 2.71 & $1.03 \mathrm{E}-06$ \\
\hline & muscle development & 21 & 9.19 & 2.29 & I.IOE-04 \\
\hline & regulation of long-term neuronal synaptic plasticity & 4 & 0.67 & 5.98 & 7.77E-04 \\
\hline & regulation of muscle contraction & 14 & 3.01 & 4.65 & 1.97E-08 \\
\hline & striated muscle contraction & 9 & 2.51 & 3.59 & I.89E-04 \\
\hline & synaptic transmission & 32 & 15.87 & 2.02 & 3.87E-05 \\
\hline & synaptogenesis & 4 & 0.67 & 5.98 & 7.77E-04 \\
\hline \multirow{12}{*}{$\begin{array}{l}M \\
F\end{array}$} & actin binding & 41 & 24.39 & 1.68 & $3.61 \mathrm{E}-04$ \\
\hline & calcium ion binding & 113 & 78.70 & $\mathrm{I} .44$ & 2.03E-05 \\
\hline & creatine kinase activity & 6 & 1.00 & 5.99 & 2.16E-05 \\
\hline & extracellular matrix structural constituent & 23 & 9.69 & 2.37 & 2.57E-05 \\
\hline & $\begin{array}{l}\text { extracellular matrix structural constituent conferring tensile } \\
\text { strength }\end{array}$ & 13 & 4.51 & 2.88 & I.48E-04 \\
\hline & ion channel activity & 44 & 25.40 & 1.73 & I.05E-04 \\
\hline & kainate selective glutamate receptor activity & 4 & 0.67 & 5.98 & 7.77E-04 \\
\hline & motor activity & 30 & 13.03 & 2.30 & $3.33 \mathrm{E}-06$ \\
\hline & protein binding & 502 & 443.45 & 1.13 & I.87E-04 \\
\hline & structural constituent of cytoskeleton & 29 & 13.70 & 2.12 & 3.17E-05 \\
\hline & structural constituent of muscle & 15 & 4.01 & 3.74 & 5.99E-07 \\
\hline & structural molecule activity & 64 & 37.76 & 1.69 & $6.88 \mathrm{E}-06$ \\
\hline
\end{tabular}

ways as a result of the disease. Bimodal genes have also been implicated in congestive heart failure, Alzheimer's disease, arteriosclerosis, breast neoplasms, hypertension, myocardial infarction, obesity, and rheumatoid arthritis. Future studies are needed for a comprehensive portrayal of their roles in these various diseases.

\section{Transcription factors and bimodal gene expression}

Approximately 15\% of transcription factors are bimodal. Comparison of our bimodal gene list with the transcription factor list obtained from the Transfac Professional
Database $[44,45]$ revealed 76 out of a total 525 transcription factors on the MG-U74Av2 array as bimodal (see Additional file 3). In turn, binding sites for these transcription factors have been identified for 91 genes with Entrez gene IDs, 79 of which were on the MG-U74Av2 array. Only 25 out of these 79 genes were bimodal, indicating that the set of bimodal transcription factors may not be solely responsible for their regulation. Nevertheless, genes that are regulated or co-regulated by bimodal transcription factors are enriched in some of the same KEGG pathways as bimodal genes (Table 7), including 


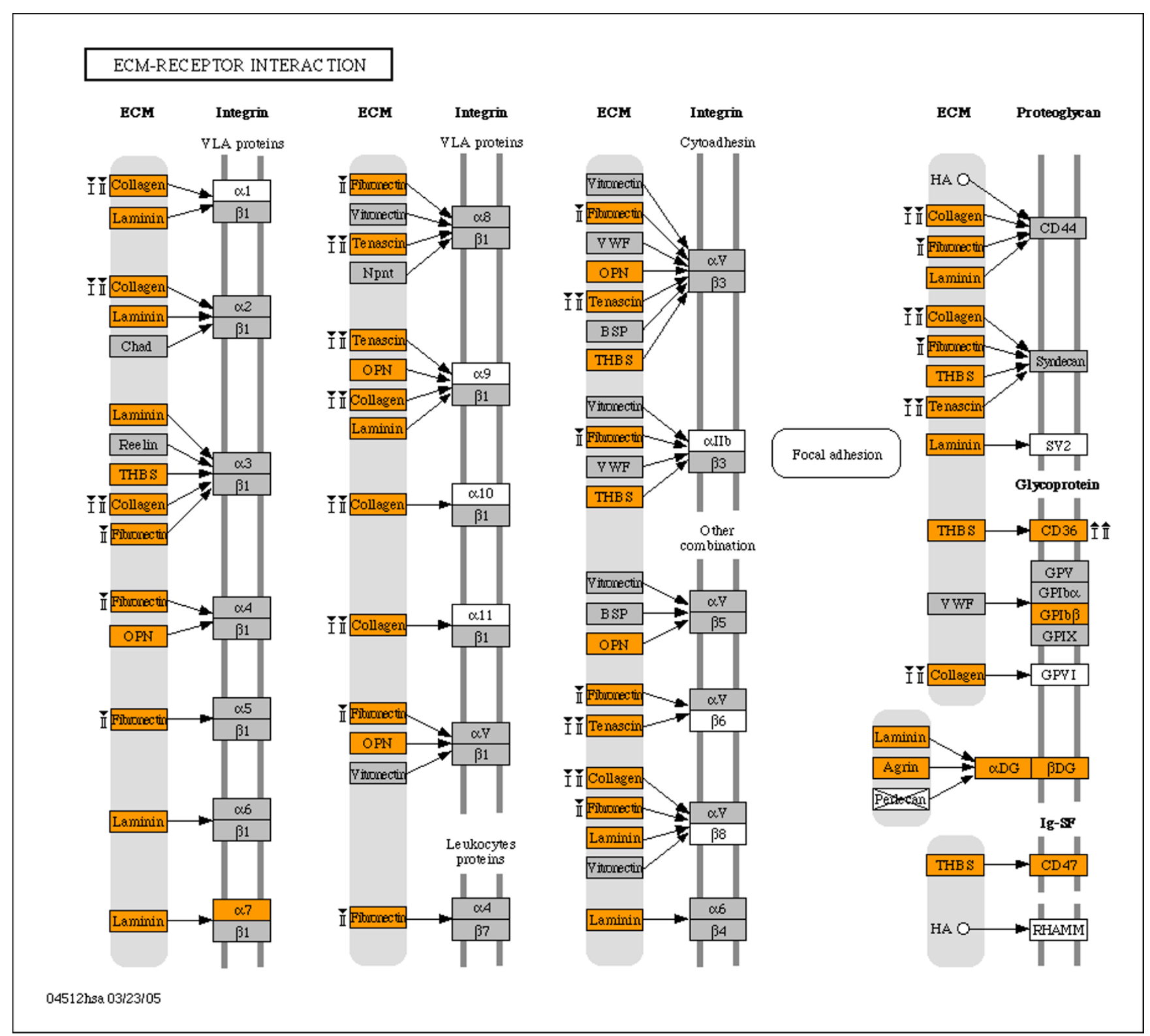

Figure 2

Bimodal genes highlighted in KEGG ECM-receptor interaction diagram. Nodes representing switch-like genes are colored orange; remaining genes on the MG-U74Av2 array are shown in grey, and white blocks designate genes not on the array. Genes not in the organism-specific pathway for mouse are crossed out. Genes identified as switching in skeletal muscle samples with diabetes type I and type II are labeled with "I" and "II", respectively, with arrows indicating the direction of change in the disease state ( $\boldsymbol{\Delta}$ is low-to-high; $\boldsymbol{\nabla}$ is high-to-low).

cell communication and ECM-receptor interaction. The GO categories for the genes co-regulated by switch-like transcription factors also intersect with GO categories of switch-like genes that are not transcription factors (Table 8 ). Additional file 3 shows that genes coding transcription factors that are involved in development such as the homeo box genes are switch-like. As the list of known transcription factors and their binding sites grow in the near future, more definitive relationships between bimodal genes and transcription factors are likely to emerge.

\section{Discussion}

This article presents a comprehensive list of bimodal genes in the mouse genome. We used an automated statistical algorithm that is similar to the approach used in the detection of bimodality in blood glucose distribution 


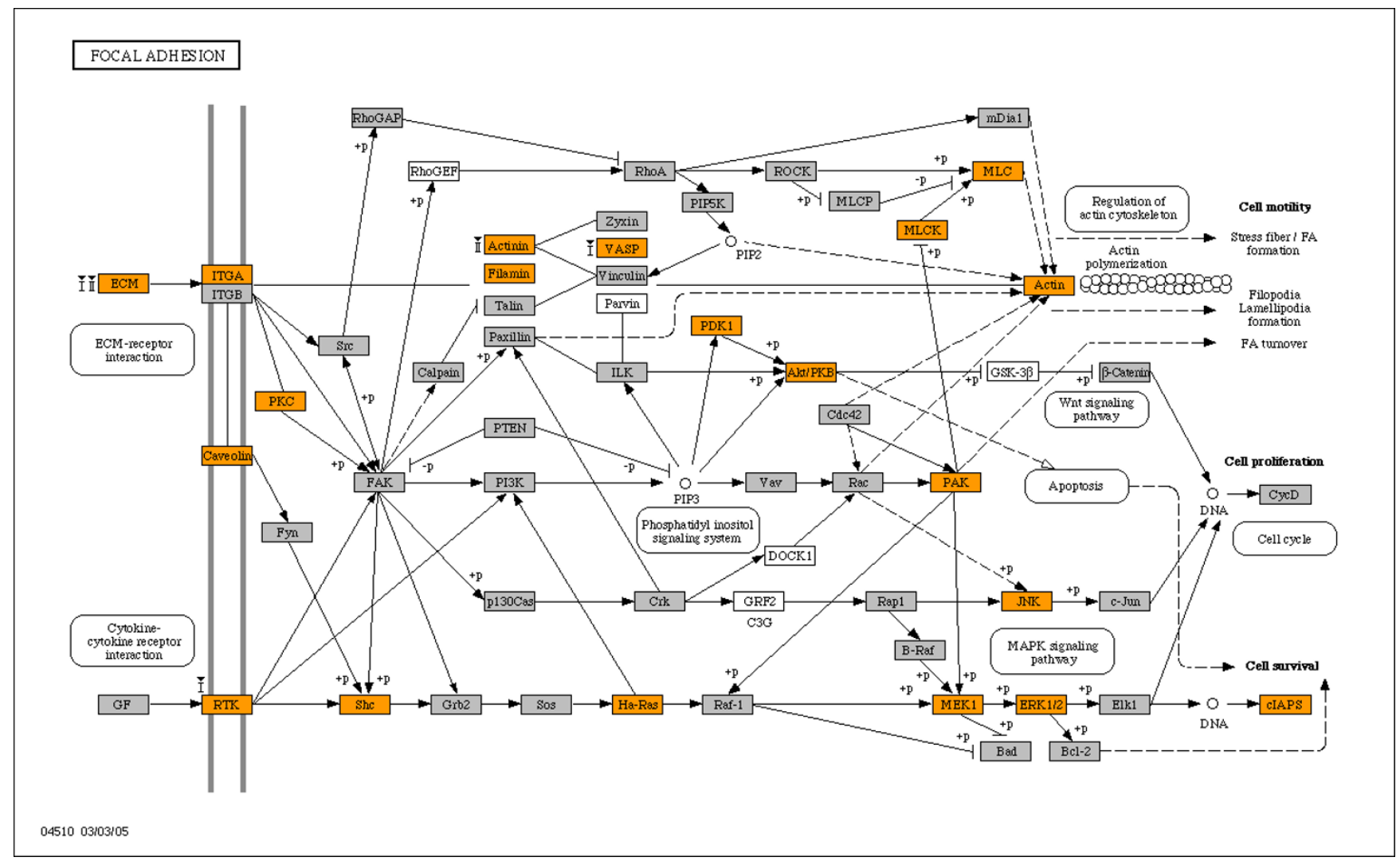

Figure 3

Bimodal genes highlighted in KEGG focal adhesion diagram. Nodes representing switch-like genes are colored orange; remaining genes on the MG-U74Av2 array are shown in grey, and white blocks designate genes not on the array. Genes identified as switching in skeletal muscle samples with diabetes type I and type II are labeled with "I" and "II", respectively, with arrows indicating the direction of change in the disease state ( $\boldsymbol{\Delta}$ is low-to-high; $\boldsymbol{\nabla}$ is high-to-low).

$[46,47]$ in order to identify bimodal, switch-like genes in a large-scale microarray database for murine tissue. Bimodal gene expression is either in a "high" or "low" expression mode, indicating switch-like regulation at the transcript level. Our automated analysis revealed over $15 \%$ of the genes in the mouse genome as bimodal (switch-like). These bimodal genes are enriched in cell communication pathways and are also enriched in such biological processes as cell adhesion, synaptic transmission, and ion transport. Moreover, bimodal genes associ- ate with a large number of disease types including diabetes type I and II, hypertension, and cancer. Because a large portion of bimodal gene products are positioned in the extracellular region, the list we present in this study provides potential biomarker targets for early detection and accurate classification of complex diseases.

Although we have paid considerable attention to the statistics of identifying bimodal genes from the large-scale microarray data, our list of bimodal genes may change

Table 5: Switch-like genes identified in alternate modes of expression in diabetes. Quantities of bimodal genes that are in alternate modes between healthy tissue and disease tissue are shown for diabetes type I and II.

\begin{tabular}{llcccccc}
\hline & Tissue type: & Adipose & Heart & Liver & Muscle & Pancreas & Peripheral Blood \\
\hline Type I diabetes & "low" to "high" & --- & 13 & --- & 37 & 16 & 9 \\
& "high" to "low" & --- & 9 & --- & 130 & 2 & 16 \\
\hline \multirow{2}{*}{ Type II diabetes } & "low" to "high" & 2 & --- & 11 & 25 & 16 & --- \\
& "high" to "low" & 3 & --- & 14 & 142 & 3 & -- \\
\hline
\end{tabular}


Table 6: Enriched KEGG pathways for switch-like genes identified in alternate modes of expression in diabetes. Enriched KEGG pathways are shown for bimodal genes that switch states between healthy tissue and type I and II diabetes (TI and T2, respectively). Enrichment scores are the number of observed genes over the number of expected genes. P-values were computed using the hypergeometric distribution.

\begin{tabular}{|c|c|c|c|c|c|c|}
\hline & Tissue & KEGG pathway & Genes observed & Genes expected & Ration of enrichment & $P \leq 0.01$ \\
\hline & Heart & --- & --- & --- & --- & --- \\
\hline \multirow[t]{12}{*}{ TI } & Muscle & Antigen processing and presentation & 9 & 1.05 & 8.60 & 8.IIE-07 \\
\hline & & Cell communication & 7 & 1.58 & 4.43 & $9.89 \mathrm{E}-04$ \\
\hline & & Cell adhesion molecules (CAMs) & 8 & 1.73 & 4.63 & 3.19E-04 \\
\hline & & ECM-receptor interaction & 7 & 1.18 & 5.95 & $1.60 \mathrm{E}-04$ \\
\hline & & Focal adhesion & 9 & 2.66 & 3.38 & $1.38 \mathrm{E}-03$ \\
\hline & & Leukocyte transendothelial migration & 8 & 1.58 & 5.06 & I.72E-04 \\
\hline & & Natural killer cell mediated cytotoxicity & 6 & 1.67 & 3.59 & 6.47E-03 \\
\hline & & Type I diabetes mellitus & 5 & 0.77 & 6.48 & 9.67E-04 \\
\hline & Pancreas & Benzoate degradation via hydroxylation & 1 & 0.01 & 101.01 & $9.86 \mathrm{E}-03$ \\
\hline & & Leukocyte transendothelial migration & 3 & 0.17 & 17.62 & $6.02 \mathrm{E}-04$ \\
\hline & & Tight junction & 2 & 0.15 & 13.12 & $9.92 \mathrm{E}-03$ \\
\hline & Peripheral blood & --- & --- & --- & --- & --- \\
\hline \multirow[t]{10}{*}{$\mathrm{T} 2$} & Adipose & --- & --- & --- & --- & --- \\
\hline & Liver & PPAR signaling pathway & 2 & 0.15 & 13.47 & $9.52 \mathrm{E}-03$ \\
\hline & Muscle & Antigen processing and presentation & 8 & 1.05 & 7.64 & $8.42 \mathrm{E}-06$ \\
\hline & & Cell communication & 6 & 1.58 & 3.80 & $4.92 \mathrm{E}-03$ \\
\hline & & Cell adhesion molecules (CAMs) & 8 & 1.73 & 4.63 & 3.19E-04 \\
\hline & & ECM-receptor interaction & 6 & 1.18 & 5.10 & I.09E-03 \\
\hline & & Leukocyte transendothelial migration & 8 & 1.58 & 5.06 & $1.72 \mathrm{E}-04$ \\
\hline & & Natural killer cell mediated cytotoxicity & 6 & 1.67 & 3.59 & 6.47E-03 \\
\hline & & Type I diabetes mellitus & 5 & 0.77 & 6.48 & 9.67E-04 \\
\hline & Pancreas & -- & --- & --- & --- & --- \\
\hline
\end{tabular}

with time as microarray data obtained with the same Affymetrix system expands to include tissue types not considered in this study. Nevertheless, the list that we present in this article is stable under deletion of gene expression outliers from the data. Although, as discussed in the Background section, a number of genes from various species have been identified in the literature as bimodal or switch-like previously, to our knowledge, the list that we present ( 1519 genes) is yet the most comprehensive and contains important information on gene regulation in health and disease at the transcript level. Although the list annotates bimodal genes for the murine genome, their orthologs presented for the human genome provide a core candidate list for the bimodal genes in the human genome. Our automated method for annotating bimodal genes will yield a comprehensive list for the human genome with the availability of a comprehensive set of standardized microarray data for large numbers of well controlled tissue samples.

Table 7: Enriched KEGG pathways for genes regulated by switch-like transcription factors. Enrichment scores are the number of observed genes over the number of expected genes. P-values were computed using the hypergeometric distribution.

\begin{tabular}{lcccc}
\hline KEGG pathway & Genes observed & Genes expected & Ration of enrichment & P-values $\leq 0.0$ I \\
\hline Antigen processing and presentation & 6 & 0.64 & 9.40 & $3.07 \mathrm{E}-05$ \\
Cell adhesion molecules (CAMs) & 5 & 0.97 & 5.17 & $2.54 \mathrm{E}-03$ \\
Cell Communication & 5 & 1.01 & 4.96 & $3.05 \mathrm{E}-03$ \\
Circadian rhythm & 3 & 0.19 & 5.19 & $6.45 \mathrm{E}-04$ \\
ECM-receptor interaction & 4 & 0.74 & 6.94 & $5.94 \mathrm{E}-03$ \\
Maturity onset diabetes of the young & 3 & 0.43 & 6.07 & $8.55 \mathrm{E}-03$ \\
PPAR signaling pathway & 5 & 0.82 & 12.60 & $1.22 \mathrm{E}-03$ \\
Type I diabetes mellitus & 7 & 0.56 & 6.07 & $7.63 \mathrm{E}-07$ \\
Type Il diabetes mellitus & 4 & 0.66 & & $3.86 \mathrm{E}-03$
\end{tabular}


Table 8: Enriched GO terms for genes regulated by switch-like transcription factors. Terms are organized by cellular component (CC), biological process (BP), and molecular function (MF). Enrichment scores are the number of observed genes over the number of expected genes. P-values were computed using the hypergeometric distribution.

\begin{tabular}{|c|c|c|c|c|c|}
\hline \multicolumn{2}{|c|}{ GO term } & \multirow{2}{*}{$\begin{array}{c}\text { Genes observed } \\
2\end{array}$} & \multirow{2}{*}{$\begin{array}{c}\text { Genes expected } \\
0.04\end{array}$} & \multirow{2}{*}{$\begin{array}{c}\text { Ration of enrichment } \\
48.58\end{array}$} & \multirow{2}{*}{$\begin{array}{c}\text { P-values } \leq 0.001 \\
4.18 \mathrm{E}-04\end{array}$} \\
\hline $\mathrm{CC}$ & collagen type I & & & & \\
\hline & external side of plasma membrane & 6 & 0.93 & 6.48 & $2.70 \mathrm{E}-04$ \\
\hline & extracellular matrix (sensu Metazoa) & 8 & 1.63 & 4.92 & I.80E-04 \\
\hline & extracellular region & 14 & 4.43 & 3.16 & $9.44 \mathrm{E}-05$ \\
\hline & extracellular space & 30 & 13.44 & 2.23 & $5.68 \mathrm{E}-06$ \\
\hline & MHC class I protein complex & 3 & 0.14 & 20.82 & 2.77E-04 \\
\hline \multirow[t]{6}{*}{$\mathrm{BP}$} & $\begin{array}{l}\text { antigen processing and presentation of endogenous peptide } \\
\text { antigen via MHC class I }\end{array}$ & 2 & 0.04 & 48.58 & 4. $18 \mathrm{E}-04$ \\
\hline & $\begin{array}{l}\text { antigen processing and presentation of peptide antigen via } \\
\text { MHC class I }\end{array}$ & 3 & 0.14 & 20.82 & 2.77E-04 \\
\hline & defense response & 6 & 1.01 & 5.95 & 4.34E-04 \\
\hline & glucose transport & 4 & 0.23 & 17.67 & 4.92E-05 \\
\hline & immune response & 11 & 3.23 & 3.40 & 3.07E-04 \\
\hline & rhythmic process & 3 & 0.19 & 16.19 & $6.45 \mathrm{E}-04$ \\
\hline \multirow[t]{2}{*}{ MF } & extracellular matrix structural constituent & 5 & 0.56 & 9.00 & I.84E-04 \\
\hline & structural constituent of bone & 2 & 0.04 & 48.58 & 4. $18 \mathrm{E}-04$ \\
\hline
\end{tabular}

Recent literature points to examples of bimodal genes involved in feedback and feedforward motifs in gene regulation networks [48-50]. Bimodal gene expression associated with switch-like regulation was shown to be a direct consequence of DNA methylation at cis-regulatory sequences at least in the case of E-coli metabolic gene circuitry [51]. This observation is consistent with our finding that only a small number of transcription factors are bimodal and those transcription factors in turn only regulate a small portion of the remaining bimodal genes.

Our study indicates that in a number of complex diseases such as diabetes type I and II, the stable inheritance of the normal mode of expression in bimodal genes is compromised. For example, bimodal genes coding for collagen subunits are "low" rather than "high" in skeletal muscle for diabetes type I and II relative to healthy samples. In addition, type II diabetes has the fibronectin subunit gene "low" rather than "high" in the same tissue. Perhaps, in compensation, collagen receptor CD36 becomes highly expressed in both diabetes types. Our comprehensive list of bimodal genes in the mouse will be useful in identifying disease-phenotypic alterations in gene regulation in diseases such as cancer, hypertension and diabetes.

For the interest of assessing the diagnostic potential of switch-like genes as biomarkers, we compared our switchlike gene list with previously published lists of serum proteins and disease genes. Mouse orthologs were obtained for serum proteins identified in the HuPO PPP, including the 3020 two-plus peptide list and 889 high-confidence lists $[52,53]$. We found that nearly a quarter of the highconfidence plasma proteins were bimodal. Although these results may change as more accurate proteomic measurements are available, it indicates the potential of switch-like genes as biomarkers for the classification of disease subtypes.

We compared our list of bimodal genes with disease gene sets for mouse obtained from the RGD Disease Portal [54]. On the average, we identified that bimodal genes account for $15 \%$ of the genes within disease gene lists for congestive heart failure, Alzheimer's disease, arteriosclerosis, breast neoplasms, cerebrovascular accident, hypertension, myocardial infarction, obesity, rheumatoid arthritis, and diabetes mellitus types I and II. Among these bimodal genes, $30 \%$ were serum protein encoding genes, suggesting their potential to serve as biomarkers.

\section{Conclusion}

This research identified a large set of mouse genes as switch-like by assembling and analyzing a large collection of microarray data encompassing diverse tissue types. Genes with bimodal, switch-like control were shown to be enriched within the cell communication pathways and the extracellular environment. The modes of expression for a large majority of such genes were tissue-selective. Moreover, a significant number of these switch-like genes switched between modes of expression in diabetic compared to healthy samples in a number of tissue types. These findings comprise an important first step in identifying altered states of gene switches in complex diseases such as hypertension, obesity and cancer.

Bimodal expression implicates strong regulation at the transcript level. Switch-like regulation can influence pro- 
tein activity in cases where protein abundance parallels transcript level, as is observed with proteins such as cytokines [55,56]. Bimodal gene expression provides a means for the cell to enable and disable pathway functions at the transcript level. Genes with bimodal, switchlike control are involved in communication pathways that play crucial roles in determining cell phenotype through interaction with the extracellular environment in health and disease. Because their expression is tightly regulated at the transcription level, they comprise a candidate set of biomarkers for a large number of disease states.

\section{Methods}

\section{Data selection}

Murine gene expression datasets (Table 1) were obtained from both the Gene Expression Omnibus (GEO,) [57-59] and ArrayExpress $[60,61]$ and limited to those providing Affymetrix GeneChip MG-U74Av2 data in CEL file format, because datasets are both current and abundant for this platform. The resulting dataset contains samples from nineteen generalized tissue types. While only one sample was obtained for stomach tissue, this does not seem to impact the detection of switch-like or tissue-selective genes identified within this tissue. Moreover, stomach tissue clusters with other digestive tissues based on the intersection of tissue-selective gene sets, as presented in the results section.

\section{Microarray normalization and annotation}

Robust Multichip Average (RMA) [62,63] expression values were computed from these CEL files, using RMAExpress software version 0.5 Release [64] with default settings, to produce a data table with genes as rows and samples as columns. All CEL files from datasets listed in Table 1 were used for normalization, but the data was limited to healthy subjects, excluding knockout and disease phenotypes, for subsequent steps in the analysis. Annotation for Entrez Gene ID, gene symbol, and KEGG pathway was retrieved March 15th, 2007 using Webgestalt (webbased gene set analysis toolkit) [42]. GO annotation, as well as missing values for Entrez Gene ID and gene symbol, was supplemented from the MG-U74Av2 annotation dated 3/8/2007, obtained directly from the Affymetrix website [65] on March 15th, 2007. The data was then imported to Matlab R2006b (The Mathworks Inc., Natick, MA, USA), where all subsequent procedures were implemented.

\section{Disease markers, serum proteins, and transcription factor annotation}

Disease gene sets for mouse were obtained from the Rat Genome Database (RGD) Disease Portal [54]. Mouse orthologs were obtained for serum protein lists available from the Human Proteome Organization (HuPO) Plasma Proteome Project (PPP) [52,53]. Entries in the PPP list were converted from International Protein Index (IPI) to human Entrez Gene ID using the IPI database for HUMAN, version 3.28, released 20 Apr 2007 [66,67]. Mouse orthologs were obtained from this list using Webgestalt. The Transfac Professional Database version 11.1 $[44,45]$ was used to identify genes as either transcription factor coding genes or transcription factor targets. Gene entries, including those encoding for transcription factors, were obtained from Transfac Gene and limited to those with Entrez Gene IDs represented on the MG-U74Av2 array.

\section{Identification of bimodal genes from estimated parameters for two-component mixtures}

Bimodal genes in the murine microarray data (Table 1) were identified using a statistical method applied to bimodality in glucose distribution [46,47]. Briefly, we tested the hypothesis $\mathrm{H}_{1}$ that gene expression distribution follows a two-component (bimodal) mixture against the hypothesis $\mathrm{H}_{0}$ of a single normal distribution, adjusted for skewness. For this purpose, we used the box-cox transformation implemented in Matlab to eliminate skewness in RMA-adjusted gene expression histograms for each gene in the microarray database [68]. Then we used the expectation maximization (EM) algorithm [69] implemented in Matlab to determine the parameters for the best-fit twocomponent normal mixture for each gene in the database. The two-component normal mixture is used to represent a bimodal distribution, where the parameters $\mu_{1}$ and $\mu_{2}$ are the component means, $\sigma_{1}$ and $\sigma_{2}$ are the component standard deviations and $\pi_{1}$ and $\pi_{2}$ represent the proportion of data within each component (note that $\pi_{2}=1-\pi_{1}$ ). The corresponding parameters for single normal distribution were calculated from the sample mean and standard deviation for each gene. The log likelihood ratio test statistic - $2 \log \lambda$ was computed for the two-component mixture hypothesis $\mathrm{H}_{1}$ versus the null hypothesis $\mathrm{H}_{0}$ of a single component as described in $[46,47]$. We estimated the $\mathrm{p}$-values for two-component mixtures by evaluating the chi-square distribution with six degrees of freedom (DF) at the values of $-2 \log \lambda$. The asymptotic null distribution for the $-2 \log \lambda$ statistic is typically represented by a chi-square distribution with DF equal to the difference in the number of parameters between the null and alternative hypotheses. However, regularity conditions for $-2 \log \lambda$ do not hold in the case of mixture models, and simulation has shown that six DF is a more accurate representation for the asymptotic null distribution when testing the alternative hypothesis of two components with unequal variance [70]. The choice of six degrees of freedom for testing two components versus a single normal provides conservative p-values and was previously used in identifying bimodality in blood glucose levels among population subsets [47]. 
Candidates for bimodal "switch-like" genes were selected as those with p-values no more than 0.001 , which produced a subset of 2166 out of 9091 unique genes on the MG-U74Av2 array. The table in Additional file 1 lists those candidate genes with $\mathrm{p}<0.01$ in order to identify additional genes that might also be considered bimodal with additional biological context, though only genes with $\mathrm{p}<0.001$ were included in our analysis to keep the false discovery rate low for the 9091 genes under consideration. In order to investigate the effect of outliers on the prediction of bimodality from gene expression data, we ran the EM procedure again within the set of bimodal candidate genes leaving out the three highest expression values for each gene. Five genes came out of the candidate list and are highlighted with an asterisk $\left({ }^{*}\right)$ in Additional file 1 though they were not excluded from our final list.

This subset of genes was further reduced by the imposing the requirement that the standardized area of intersection A (indicating type I and type II error for the estimated bimodal distribution divided by the total area) was less than 0.10. This is clarified in Figure 4A, where the dark grey region under the normal curves represents type I error and the solid black region under the normal curves represents type II error. The rationale for this step is that in order for switching to play a functional role within the cell, there must be minimal overlap between the two mixture components. This criterion reduced the number of candidate switch-like genes from 2166 to 1458. In the resulting gene list, the standardized distance between components, $\mathrm{D}=\left(\mu_{2}-\mu_{1}\right) / \min \left(\sigma_{1}, \sigma_{2}\right)$, was at least 2.5 for this remaining subset of switch-like gene candidates, confirming the statistical power of our analysis [71]. Figure 4B illustrates the reduction in switch-like gene candidates based on several cutoff values for the type I and II error rate.

\section{Assigning expression values to high/low modes for switch- like genes}

The switching threshold for each gene was defined at the intersection of the density curves for the two components of the mixture. This switching threshold is mapped back onto the log RMA expression axis (labeled as $X_{T}$ in Figure $4 \mathrm{~A})$ with a reverse box-cox transformation. A gene expression sample greater than $X_{T}$ for that gene was classified as having high expression, while a sample less than $X_{T}$ was classified has having low expression. Standardized area of intersection A was restricted to less than 0.1 in order to keep classification error to a minimum in the assignment of "high" and "low" states to switch-like genes.

\section{Developing a dendrogram for tissue similarity using the concept of tissue selectivity}

Nineteen tissue types for which we have extensive gene expression profiling have been clustered in dendrogram using a coexpression matrix. Elements of the coexpression
A)

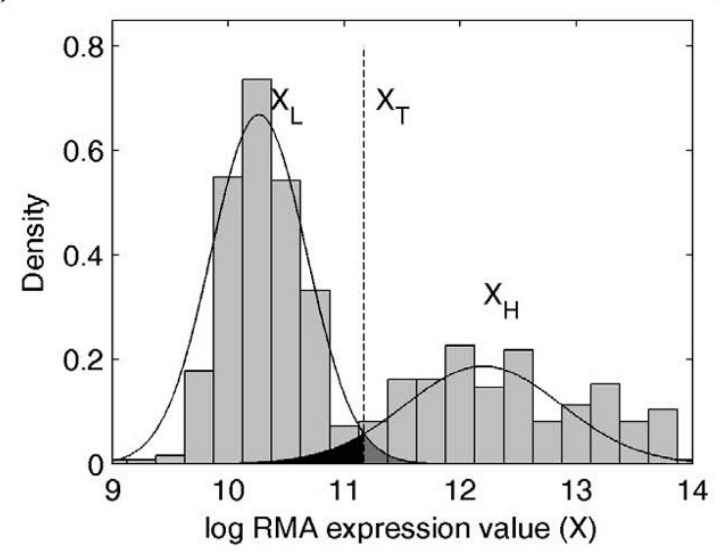

B)

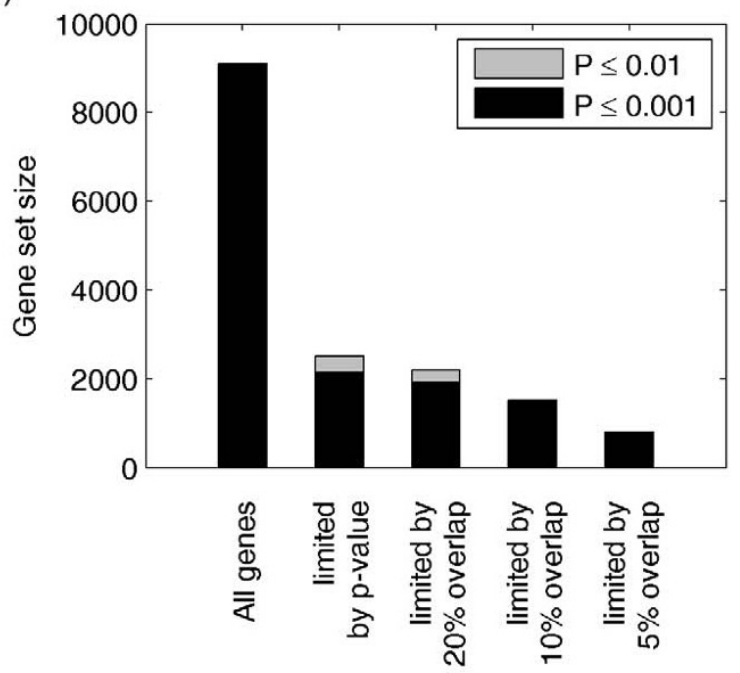

\section{Figure 4}

Identification of switch-like genes with bimodal gene expression. A) The histogram and normal mixture probability density function ( $\mathrm{pdf}$ ) for a bimodal candidate gene. B) Bar graph representing gene set sizes during switch-like gene candidate selection process. 
matrix were selected from the larger gene set with the restriction that a gene in the subset must be expressed in the high mode for the majority of the samples in at least one tissue. For this purpose, the gene expression values for switch-like genes were converted to binary values corresponding to the high and low modes of two-component distribution. Gene expression within a single tissue type was modeled as a Bernoulli process (binomial distribution) with equal probabilities of high and low. Based on this model, a gene that is not selectively expressed within a given tissue type should be evenly distributed between the high and low modes. A gene that is selectively expressed within a given tissue type would show a significant bias for the high mode and low corresponding pvalue. We established p-values for a gene to be selectively expressed within each tissue type from the binomial distribution, where the number of trials equals the number of samples for that tissue type and the number of successes equals the number of samples with values in the high expression component. Conversely, p-values for a gene to be selectively repressed within each tissue type were established based on the number of samples with values in the low expression component. Tissue-selective genes were selected as those with $\mathrm{p}<0.01$ for at least one of the nineteen general tissue types.

\section{Functional enrichment analysis}

KEGG pathway and GO annotations were used to compute functional enrichment scores for all switch-like genes. Functional enrichment analysis was performed in Matlab by calculating the ratio of genes belonging to a functional category within a gene set of interest against the total number of genes belonging to that functional category within the set of genes on the MG-U74Av2 array. Enrichment p-values were computed from a hypergeometric distribution. The p-value cutoffs were selected at 0.01 for KEGG pathways and 0.001 for GO terms, to reduce the false discovery rate. The set of candidate bimodal genes contained 153 unique KEGG pathways and 321 unique GO cellular component terms, for which an expected 1.5 and 0.3 of the terms may appear significant by chance at these p-value cutoffs, respectively.

\section{Comparisons of health and disease states}

Additional MG-U74Av2 samples were used to identify alternate switching modes of switch-like genes in diabetes type I and II. These samples are listed in Table 2 and represent adipose, heart, liver, skeletal muscle, pancreas, and peripheral blood. Bimodal genes were identified as altered in disease for a single tissue by again modeling the samples as a binomial distribution. Genes were identified as switching in the disease state when healthy samples have a significant p-value (less that 0.01 ) in one mode while disease samples have a significant p-value (less than 0.01) for the opposite mode.

\section{Authors' contributions}

$\mathrm{AE}$ and $\mathrm{AT}$ worked together on this project. AE implemented the algorithms, performed the computations and provided a first draft for the manuscript. Both authors read and approved the final version of the manuscript.

\section{Additional material}

\section{Additional file 1}

Bimodal gene list. This table provides a comprehensive list of bimodal genes for the mouse genome including parameters used in the identification of bimodal gene expression.

Click here for file

[http://www.biomedcentral.com/content/supplementary/14712164-9-3-S1.xls]

\section{Additional file 2}

Bimodal genes with altered modes of expression in diabetes. This table identifies bimodal genes that switch between high and low modes of expression in type I and II diabetes vs. normal within various tissue types. Click here for file

[http://www.biomedcentral.com/content/supplementary/14712164-9-3-S2.xls]

\section{Additional file 3}

Transcription factor genes with bimodal expression. This table lists bimodal genes identified as transcription factor coding in the Transfac Professional Database.

Click here for file

[http://www.biomedcentral.com/content/supplementary/1471-

2164-9-3-S3.xls]

\section{Acknowledgements}

This study was supported by the National Institute of Health $(\mathrm{NIH})$ grant \#232240 and by the National science Foundation (NSF) grant \# 235327.

\section{References}

I. Hsiao LL, Dangond F, Yoshida T, Hong R, Jensen RV, Misra J, Dillon W, Lee KF, Clark KE, Haverty P, Weng Z, Mutter GL, Frosch MP, Macdonald ME, Milford EL, Crum CP, Bueno R, Pratt RE, Mahadevappa M, Warrington JA, Stephanopoulos G, Stephanopoulos G, Gullans SR: A compendium of gene expression in normal human tissues. Physiol Genomics 200I, 7:97-104.

2. White KP, Rifkin SA, Hurban P, Hogness DS: Microarray analysis of Drosophila development during metamorphosis. Science 1999, 286:2179-84.

3. Small CL, Shima JE, Uzumcu M, Skinner MK, Griswold MD: Profiling gene expression during the differentiation and development of the murine embryonic gonad. Biology of Reproduction 2005, 72:492-501.

4. Alon U, Barkai N, Notterman DA, Gish K, Ybarra S, Mack D, Levine AJ: Broad patterns of gene expression revealed by clustering analysis of tumor and normal colon tissues probed by oligonucleotide arrays. Proc Natl Acad Sci U S A 1999, 96:6745-6750.

5. Ross DT, Scherf U, Eisen MB, Perou CM, Rees C, Spellman P, lyer V, Jeffrey SS, Van de Rijn M, Waltham M, Pergamenschikov A, Lee JC, Lashkari D, Shalon D, Myers TG, Weinstein JN, Botstein D, Brown PO: Systematic variation in gene expression patterns in human cancer cell lines. Nat Genet 2000, 24:227-235.

6. Lan H, Rabaglia ME, Stoehr JP, Nadler ST, Schueler KL, Zou F, Yandell $B S$, Attie AD: Gene expression profiles of nondiabetic and diabetic obese mice suggest a role of hepatic lipogenic capacity in diabetes susceptibility. Diabetes 2003, 52:688. 
7. Kanehisa M, Goto S, Hattori M, Aoki-Kinoshita KF, Itoh M, Kawashima S, Katayama T, Araki M, Hirakawa M: From genomics to chemical genomics: new developments in KEGG. Nucleic Acids Res 2006, 34:D354-357.

8. Sandberg R, Ernberg I: The molecular portrait of in vitro growth by meta-analysis of gene-expression profiles. Genome Biol 2005, 6:R65.

9. Ertel A, Verghese A, Byers SW, Ochs M, Tozeren A: Pathway-specific differences between tumor cell lines and normal and tumor tissue cells. Mol Cancer 2006, 5:55.

10. Moloshok TD, Klevecz RR, Grant JD, Manion FJ, Speier WF 4th, Ochs MF: Application of Bayesian decomposition for analysing microarray data. Bioinformatics 2002, I 8:566-75.

II. Segal E, Yelensky R, Koller D: Genome-wide discovery of transcriptional modules from DNA sequence and gene expression. Bioinformatics 2003, I 9(Suppl I):i273-282.

12. Ge X, Yamamoto S, Tsutsumi S, Midorikawa Y, Ihara S, Wang SM, Aburatani $\mathrm{H}$ : Interpreting expression profiles of cancers by genome-wide survey of breadth of expression in normal tissues. Genomics 2005, 86:|27-4|.

13. Su Al, Cooke MP, Ching KA, Hakak Y, Walker JR, Wiltshire T, Orth AP, Vega RG, Sapinoso LM, Moqrich A, Patapoutian A, Hampton GM, Schultz PG, Hogenesch JB: Large-scale analysis of the human and mouse transcriptomes. Proc Natl Acad Sci U S A 2002 99:4465-4470.

14. Zhang W, Morris QD, Chang R, Shai O, Bakowski MA, Mitsakakis N Mohammad N, Robinson MD, Zirngibl R, Somogyi E, Laurin N, Eftekharpour E, Sat E, Grigull J, Pan Q, Peng WT, Krogan N, Greenblatt J, Fehlings M, van der Kooy D, Aubin J, Bruneau BG, Rossant J, Blencowe BJ, Frey BJ, Hughes TR: The functional landscape of mouse gene expression. I Biol 2004, 3:2I.

15. Liang S, Li Y, Be X, Howes S, Liu W: Detecting and profiling tissue-selective genes. Physiol Genomics 2006, 26: I 58-62.

16. Shyamsundar R, Kim YH, Higgins JP, Montgomery K, Jorden $M$, Sethuraman A, van de Rijn M, Botstein D, Brown PO, Pollack JR: A DNA microarray survey of gene expression in normal human tissues. Genome Biol 2005, 6:R22.

17. Vasmatzis G, Klee E, Kube DM, Therneau T, Kosari F: Quantitating Tissue Specificity of Human Genes to Facilitate Biomarke Discovery. Bioinformatics 2007, 23: | 348-I355.

18. Yanai I, Benjamin H, Shmoish M, Chalifa-Caspi V, Shklar M, Ophir R, Bar-Even A, Horn-Saban S, Safran M, Domany E, Lancet D, Shmueli O Genome-wide midrange transcription profiles reveal expression level relationships in human tissue specification. Bioinformatics 2005, 2 I :650-659.

19. Biggar SR, Crabtree GR: Cell signaling can direct either binary or graded transcriptional responses. EMBO I 2001 20:3167-3176.

20. Jõers A, Jaks V, Kase J, Maimets T: p53-dependent transcription can exhibit both on/off and graded response after genotoxic stress. Oncogene 2004, 23:6175-85.

21. Ishii T, Wallace AM, Zhang X, Gosselink J, Abboud RT, English JC, Pare PD, Sandford AJ: Stability of housekeeping genes in alveolar macrophages from COPD patients. Eur Respir J 2006 , 27:300-306.

22. Van Houten N, Mixter PF, Wolfe J, Budd RC: CD2 expression on murine intestinal intraepithelial lymphocytes is bimodal and defines proliferative capacity. Int Immunol 1993, 5:665-672.

23. Bahar R, Hartmann CH, Rodriguez KA, Denny AD, Busuttil RA, Dolle ME, Calder RB, Chisholm GB, Pollock BH, Klein CA, Vijg J: Increased cell-to-cell variation in gene expression in ageing mouse heart. Nature 2006, 441:1011-1014.

24. Warrington JA, Nair A, Mahadevappa M, Tsyganskaya M: Comparison of human adult and fetal expression and identification of 535 housekeeping/maintenance genes. Physiol Genomics 2000, 2(3): | $43-147$

25. Friese RS, Mahboubi P, Mahapatra NR, Mahata SK, Schork NJ, Schmid Schonbein GW, O'Connor DT: Common genetic mechanisms of blood pressure elevation in two independent rodent models of human essential hypertension. Am J Hypertens 2005 , 5:633-652.

26. Hovatta I, Tennant RS, Helton R, Marr RA, Singer O, Redwine JM, Ellison JA, Schadt EE, Verma IM, Lockhart DJ, Barlow C: Glyoxalase I and glutathione reductase I regulate anxiety in mice. Nature 2005, 438:662-666.
27. de Buhr MF, Mahler M, Geffers R, Hansen W, Westendorf AM, Lauber J, Buer J, Schlegelberger B, Hedrich HJ, Bleich A: Cd I4, Gbp I, and Pla2g2a: three major candidate genes for experimental IBD identified by combining QTL and microarray analyses. Physiol Genomics 2006, 25:426-434.

28. Lin KK, Chudova D, Hatfield GW, Smyth P, Anderson B: Identification of hair cycle-associated genes from time-course gene expression profile data by using replicate variance. Proc Natl Acad Sci U S A 2004, I 0 I: I 5955- I5960.

29. Lehti TM, Silvennoinen M, Kivela R, Kainulainen $H$, Komulainen J: Effects of streptozotocin-induced diabetes and physical training on gene expression of extracellular matrix proteins in mouse skeletal muscle. Am J Physiol Endocrinol Metab 2006 290:E900-907.

30. Maritzen T, Rickheit G, Schmitt A, Jentsch T]: Kidney-specific upregulation of vitamin D3 target genes in CIC-5 KO mice. Kidney Int 2006, 70:79-87.

31. Gresh L, Bourachot B, Reimann A, Guigas B, Fiette L, Garbay S, Muchardt C, Hue L, Pontoglio M, Yaniv M, Klochendler-Yeivin A: The SWI/SNF chromatin-remodeling complex subunit SNF5 is essential for hepatocyte differentiation. EMBO J 2005, 24:33। 3-3324.

32. Boxer RB, Stairs DB, Dugan KD, Notarfrancesco KL, Portocarrero CP, Keister BA, Belka GK, Cho H, Rathmell JC, Thompson CB, Birnbaum MJ, Chodosh LA: Isoform-specific requirement for Akt I in the developmental regulation of cellular metabolism during lactation. Cell Metab 2006, 4:475-490

33. Zhao P, lezzi S, Carver E, Dressman D, Gridley T, Sartorelli V, Hoffman EP: Slug is a novel downstream target of MyoD. Temporal profiling in muscle regeneration. J Biol Chem 2002, 277:3009l-30l0l.

34. Kaur S, Norkina O, Ziemer D, Samuelson LC, De Lisle RC: Acidic duodenal $\mathrm{pH}$ alters gene expression in the cystic fibrosis mouse pancreas. Am J Physiol Gastrointest Liver Physiol 2004, 287:G480-490.

35. Yamagata T, Benoist C, Mathis D: A shared gene-expression signature in innate-like lymphocytes. Immunol Rev 2006 , 21 0:52-66.

36. Shima JE, McLean DJ, McCarrey JR, Griswold MD: The murine testicular transcriptome: characterizing gene expression in the testis during the progression of spermatogenesis. Biol Reprod 2004, 7l:319-330.

37. Schultz N, Hamra FK, Garbers DL: A multitude of genes expressed solely in meiotic or postmeiotic spermatogenic cells offers a myriad of contraceptive targets. Proc Natl Acad Sci U S A 2003, 100:12201-12206.

38. Derbinski J, Gabler J, Brors B, Tierling S, Jonnakuty S, Hergenhahn M, Peltonen L, Walter J, Kyewski B: Promiscuous gene expression in thymic epithelial cells is regulated at multiple levels. J Exp Med 2005, 202:33-45.

39. Anderson MS, Venanzi ES, Klein L, Chen Z, Berzins SP, Turley SJ, von Boehmer H, Bronson R, Dierich A, Benoist C, Mathis D: Projection of an immunological self shadow within the thymus by the aire protein. Science 2002, 298: |395-|40I.

40. Vukkadapu SS, Belli JM, Ishii K, Jegga AG, Hutton JJ, Aronow BJ, Katz JD: Dynamic interaction between $T$ cell-mediated beta-cell damage and beta-cell repair in the run up to autoimmune diabetes of the NOD mouse. Physiol Genomics 2005, 2 I:201-2 I I.

4I. Herman AE, Freeman G], Mathis D, Benoist C: CD4+CD25+ T regulatory cells dependent on ICOS promote regulation of effector cells in the prediabetic lesion. J Exp Med 2004 199:|479-1489.

42. Zhang B, Kirov S, Snoddy J: WebGestalt: an integrated system for exploring gene sets in various biological contexts. Nucleic Acids Res 2005, 33:W741-748.

43. Hynes RO: Integrins: bidirectional, allosteric signaling machines. Cell 2002, I 1 0:673-687.

44. TRANSFAC database [http://www.gene-regulation.com]

45. Wingender E, Chen X, Hehl R, Karas H, Liebich I, Matys V, Meinhardt T, Pruss M, Reuter I, Schacherer F: TRANSFAC: an integrated system for gene expression regulation. Nucleic Acids Res 2000 , 28:316-319.

46. Lim TO, Bakri R, Morad Z, Hamid MA: Bimodality in blood glucose distribution: is it universal? Diabetes Care 2002, 25:2212-2217. 
47. Fan J, May S, Zhou Y, Barrett-Connor E: Bimodality of 2-h plasma glucose distributions in whites: the Rancho Bernardo study. Diabetes Care 2005, 28: | 45 I-1456.

48. Becskei A, Séraphin B, Serrano L: Positive feedback in eukaryotic gene networks: cell differentiation by graded to binary response conversion. EMBO J 200I, 20:2528-2535.

49. Dekel E, Mangan S, Alon U: Environmental selection of the feedforward loop circuit in gene-regulation networks. Phys Biol 2005, 2:8I-88.

50. Paliwal S, Iglesias PA, Campbell K, Hilioti Z, Groisman A, Levchenko A: MAPK-mediated bimodal gene expression and adaptive gradient sensing in yeast. Nature 2007, 446:46-5I.

51. Lim HN, van Oudenaarden A: A multistep epigenetic switch enables the stable inheritance of DNA methylation states. Nat Genet 2007, 39:269-275.

52. HuPO Plasma Proteome Project [http://www.bioinformat ics.med.umich.edu/hupo/ppp]

53. Omenn GS, States DJ, Adamski M, Blackwell TW, Menon R, Hermjakob H, Apweiler R, Haab BB, Simpson RJ, Eddes JS, Kapp EA, Moritz RL, Chan DW, Rai AJ, Admon A, Aebersold R, Eng J, Hancock WS, Hefta SA, Meyer H, Paik YK, Yoo JS, Ping P, Pounds J, Adkins J, Qian $X$, Wang R, Wasinger V, Wu CY, Zhao X, Zeng R, Archakov A, Tsugita A, Beer I, Pandey A, Pisano M, Andrews P, Tammen H, Speicher DW, Hanash SM: Overview of the HUPO Plasma Proteome Project: results from the pilot phase with 35 collaborating laboratories and multiple analytical groups, generating a core dataset of 3020 proteins and a publicly-available database. Proteomics 2005, 5:3226-3245.

54. Twigger SN, Shimoyama M, Bromberg S, Kwitek AE, Jacob HJ: The Rat Genome Database, update 2007 - easing the path from disease to data and back again. Nucleic Acids Res 2007 35:D658-662.

55. Shen Y, lqbal J, Huang JZ, Zhou G, Chan WC: BCL2 protein expression parallels its mRNA level in normal and malignant B cells. Blood 2004, 104:2936-2939.

56. Prabhakar U, Conway TM, Murdock P, Mooney JL, Clark S, Hedge P, Bond BC, Jazwinska EC, Barnes MR, Tobin F, Damian-lordachi V, Greller L, Hurle M, Stubbs AP, Li Z, Valoret El, Erickson-Miller C, Cass L, Levitt B, Davis HM, Jorkasky DK, Williams WV: Correlation of protein and gene expression profiles of inflammatory proteins after endotoxin challenge in human subjects. DNA Cell Biol 2005, 24:410-43I.

57. Gene Expression Omnibus [http://www.ncbi.nlm.nih.gov/geo/]

58. Barrett T, Troup DB, Wilhite SE, Ledoux P, Rudnev D, Evangelista C, Kim IF, Soboleva A, Tomashevsky M, Edgar R: NCBI GEO: mining tens of millions of expression profiles - database and tools update. Nucleic Acids Res 2007, 35:D760-765.

59. Edgar R, Domrachev M, Lash AE: Gene Expression Omnibus: NCBI gene expression and hybridization array data repository. Nucleic Acids Res 2002, 30:207-2 I0.

60. ArrayExpress [http://www.ebi.ac.uk/arrayexpress/]

6I. Brazma A, Parkinson H, Sarkans U, Shojatalab M, Vilo J, Abeygunawardena N, Holloway E, Kapushesky M, Kemmeren P, Lara GG Oezcimen A, Rocca-Serra P, Sansone SA: ArrayExpress - a public repository for microarray gene expression data at the EBI. Nucleic Acids Res 2003, 31:68-71.

62. Irizarry RA, Bolstad BM, Collin F, Cope LM, Hobbs B, Speed TP: Summaries of Affymetrix GeneChip probe level data. Nucleic Acids Res 2003, 31:el5.

63. Bolstad BM, Irizarry RA, Astrand M, Speed TP: A comparison of normalization methods for high density oligonucleotide array data based on variance and bias. Bioinformatics 2003, 19:185-193.

64. RMAExpress [http://rmaexpress.bmbolstad.com/]

65. Affymetrix [http://www.affymetrix.com]

66. International Protein Index database [http://www.ebi.ac.uk/IPI/ ]

67. Kersey PJ, Duarte J, Williams A, Karavidopoulou Y, Birney E, Apweiler R: The International Protein Index: An integrated database for proteomics experiments. Proteomics 2004, 4:1985-1988.

68. MacLean C], Morton NE, Elston RC, Yee S: Skewness in Commingled Distributions. Biometrics 1976, 32:695-699.

69. Dempster AP, Laird NM, Rubin DB: Maximum likelihood from incomplete data via the EM algorithm. J Royal Stat Soc 1977, 39:1-38.
70. McLachlan G]: On bootstrapping the likelihood ratio test stastistic for the number of components in a normal mixture. Applied Statistics 1987, 36:318-324.

7I. Ning Y, Finch S): The likelihood ratio test with the box-cox transformation for the normal mixture problem: Power and sample size study. Comm Stat Simul Comp 2004, 33:553-565.
Publish with Biomed Central and every scientist can read your work free of charge

"BioMed Central will be the most significant development for disseminating the results of biomedical research in our lifetime. "

Sir Paul Nurse, Cancer Research UK

Your research papers will be:

- available free of charge to the entire biomedical community

- peer reviewed and published immediately upon acceptance

- cited in PubMed and archived on PubMed Central

- yours - you keep the copyright

Submit your manuscript here:

http://www.biomedcentral.com/info/publishing_adv.asp
BioMedcentral 